\title{
Effect of Secondary Flows on Heat Transfer of a Gas Turbine Blade
}

\author{
Hesham M. El-Batsh, Sameh A. Nada, Samia Nasreldin Abdo, and Abdelgalil A. El-Tayesh \\ Mechanical Engineering Department, Benha Faculty of Engineering, Benha University, Benha 13512, Egypt \\ Correspondence should be addressed to Hesham M. El-Batsh; helbatsh@yahoo.com
}

Received 29 April 2013; Revised 11 August 2013; Accepted 13 August 2013

Academic Editor: Arthur Lees

Copyright (C) 2013 Hesham M. El-Batsh et al. This is an open access article distributed under the Creative Commons Attribution License, which permits unrestricted use, distribution, and reproduction in any medium, provided the original work is properly cited.

\begin{abstract}
This study presents experimental and numerical investigation for three-dimensional heat transfer characteristics in a turbine blade. An experimental setup was installed with a turbine cascade of five-blade channels. Blade heat transfer measurements were performed for the middle channel under uniform heat flux boundary conditions. Heat was supplied to the blades using twentynine electric heating strips cemented vertically on the outer surface of the blades. Distributions of heat transfer coefficient were obtained at three levels through blade height by measuring surface temperature distribution using thermocouples. To understand heat transfer characteristics, surface static pressure distributions on blade surface were also measured. Numerical investigation was performed as well to extend the investigation to locations other than those measured experimentally. Three-dimensional nonisothermal, turbulent flow was obtained by solving Reynolds averaged Navier-Stokes equations and energy equation. The shear stress transport $k$ - $\omega$ model was employed to represent turbulent flow. It was found through this study that secondary flow generated by flow deflection increases heat transfer coefficient on the blade suction surface. Separation lines with high heat transfer coefficients were predicted numerically with good agreement with the experimental measurements.
\end{abstract}

\section{Introduction}

The performance of gas turbine engines is determined by their specific work and thermal efficiency which are improved by increasing combustor gas exit temperature. However, increasing combustor exit temperature increases the thermal load on the first stage of a gas turbine engine. Consequently, heat transfer characteristics are required for engines safe operation. In addition, effective cooling of turbine blades is required to reduce thermal load and allow safe and effective operation at high levels of gas temperatures. To optimize blade cooling, exact understanding of surface heat transfer of a turbine blade is necessary. Heat transfer mechanism in gas turbine blades is very complicated due to the complexity of flow pattern around the blades. Flow in turbine cascades is characterized by different flow features which include accelerating flow on blade pressure side and accelerating and decelerating flow on blade surface. In addition, the passage flow is characterized by boundary layer effects, secondary flow generated by the passage pressure gradients, and vertical flow structures such as the leading edge horseshoe vortices. These flows affect the three-dimensional heat transfer in gas turbine blades.

Laboratory measurements are available in the literature and conducted to understand two-dimensional heat transfer at blade midspan. Extensive investigation on midspan heat transfer of a turbine blade has been performed by Arts et al. [1]. They studied fluid flow and heat transfer in a highly loaded transonic linear turbine guide vane cascade at the design incidence. A set of experimental studies were performed to investigate the effect of Reynolds number and Mach number as well as free stream turbulence intensity on heat transfer characteristics of a turbine cascade. Later, numerous numerical studies had used the measured data obtained by Arts et al. [1] to evaluate the accuracy of their two-dimensional numerical calculations [2-10].

Researchers also used data obtained by Arts et al. [1] for prober selection of turbulence models and to investigate the effect of turbulence intensity and length scale on heat transfer on turbine blades (e.g., Garg and Ameri [11]). 
Two-dimensional measurements are very useful for understanding blade heat transfer at midspan and provide useful data for numerical model validation. However, twodimensional study cannot simulate the real heat transfer mechanism in a gas turbine blade where three-dimensional flow is developed in turbine blade passages due leading edge horseshoe vortices. Langston et al. [12], Sieverding [13], and Wang et al. [14] provided complete overview on the basic aspects of secondary flow in turbine blade passage. Secondary flow affects the aerodynamic performance of a turbine cascade and changes heat transfer characteristics from the hot fluid to the blade and end-wall surfaces.

Figure 1 shows the features of the secondary flow generated in turbine cascades as presented by Wang et al. [14]. Due to the blockage presented by the leading edge, the incoming end-wall boundary layer is subjected to a stagnation pressure gradient. This causes the boundary layer to undergo threedimensional separation and to roll up into a horseshoe vortex, as illustrated. The legs of the horseshoe vortex pass to either side of the blade. The suction side leg travels around the blade and its lift off line later intersects the blade suction surface. The pressure side leg moves into the blade passage and merges with the main passage vortex, which itself moves across to the suction surface of the neighboring blade under the influence of the passage pressure field. The figure indicates also that corner vortices are generated near the end-wall.

Giel et al. [15] studied the effect of Reynolds number, exit Mach number, and inlet turbulence intensity on threedimensional heat transfer using experimental measurements. The results were compared to numerical calculations using three-dimensional Navier-Stokes code. The comparison illustrated regions of good agreement, while other regions need modeling improvement. The results also showed that heat transfer near end-wall suction surface region increased by secondary flow. Pecnik et al. [16] presented three-dimensional numerical investigations on a transonic turbine guide vane using different turbulence models on the predication of heat transfer and secondary flow effects. Garg and Ameri [11] performed numerical simulation using $k-\omega$ model and a shear stress transport (SST) $k-\omega$ model and compared their results with heat transfer measurements on a transonic turbine blade of Giel et al. [15]. The results showed that the $k-\omega$ model and SST $k-\omega$ model compare well on pressure side of the blade and leading edge. For the suction side, the SST $k-\omega$ model resolves the passage vortex yielding a better comparison with experimental data than $k-\omega$ model. Johan et al. [17] predicted numerically the secondary flow downstream of a highly loaded low pressure turbine outlet guide vane cascade. Papa [18] studied the effect of secondary flow on heat transfer on blade and hub wall surfaces of a gas turbine engine. The measurements are performed in a linear cascade composed of five blades. Tests are conducted at a Reynolds number of $6 \times 10^{5}$. The RANS carried out to simulate the flow and heat/mass transfer using SST $k$ - $\omega$ model is evaluated through a comparison with the experimental data. Results show that the SST $k-\omega$ model predicted well heat transfer on the airfoil surface and formations and development of the horseshoe vortex. The heat transfer on the end-wall was also well predicated.

Lee and park [19] investigate the effect of incidence angle on the end-wall heat transfer; surface flow visualization

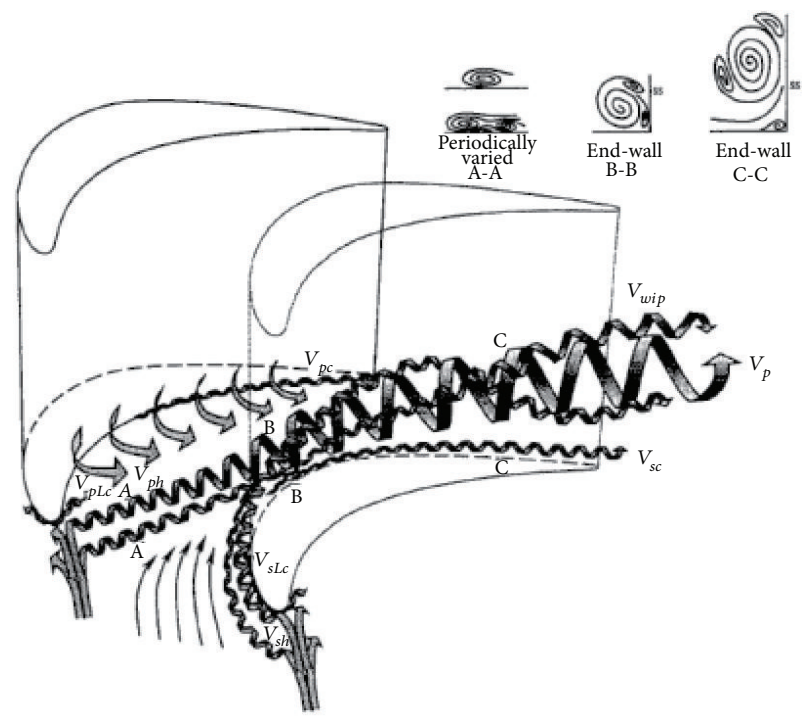

$V_{s h}$ : suction side leg of horseshoe vortex system

$V_{p h}$ : pressure side leg of horseshoe vortex system

$V_{p}$ : passage vortex

$V_{w i p}$ : wall vortex induced by the passage vortex

$V_{s L c}$ : suction side leading edge corner vortex

$V_{p L c}$ : pressure side leading edge of corner vortex

$V_{s c}$ : suction side corner vortex

$V_{p c}$ : pressure side corner vortex

Figure 1: Secondary flow model by Wang et al. [14].

and heat transfer measurements are carried out at the inlet Reynolds number of $2.78 \times 10^{5}$ and for incidence angles of $-10^{\circ},-5^{\circ}, 0^{\circ}, 5^{\circ}$, and $10^{\circ}$. The results show that in the negative incidence case, the mass transfer is less influenced by the leading edge horseshoe vortex and by suction side corner vortex. Lynch et al. [20] studied the effect of three-dimensional end-wall nonaxisymmetric contouring on the end-wall heat transfer for a low pressure turbine blade. End-wall oil flow visualization indicated that the passage vortex strength is reduced for contoured end-wall geometry as compared with flat end-wall. Lynch et al. [21] used the commercial computational fluid dynamic software FLUENT to simulate the effect of flat end-wall and three-dimensional nonaxisymmetric contoured end-wall on the end-wall heat transfer for a low pressure turbine blade. They found that the heat transfer for a nonaxisymmetric contour relative to a flat end-wall showed fair agreement to the experiment.

Morata et al. [22] provided 3D numerical investigation to predicated the wall heat transfer distribution in a highly loaded turbine guide vane with RANS and two LES approaches (structured and unstructured). The predicated heat transfer from both RANS and LES was compared with the experimental measurements Arts et al. [1].

Qureshi et al. [23] studied the effect of turbine inlet temperature distortion on rotor surface and casing heat transfer and aerodynamic in a transonic turbine stage test facility at scaled engine conditions. Three-dimensional simulations conducted using the Rolls-Royce in house CFD solver HYDRA and are compared with the experimental results. 
The literature review showed that the previous studies focused on the investigation of different numerical techniques and turbulence models on turbine blade heat transfer. They also examined the effect of Reynolds number and the free stream turbulence intensity on blade heat transfer. There are limited studies providing information on the effect of the secondary flow through turbine cascades. The aim of the present study is to investigate the three-dimensional heat transfer and flow characteristics through a turbine cascade. The study aims also to understand the process of heat transfer and the effect of secondary flow on the distribution of the convection heat transfer coefficient. Flow and heat transfer characteristics are examined at different Reynolds numbers.

\section{Experimental Technique}

2.1. Experimental Setup. The experimental setup used in the present study was constructed in the fluid mechanics laboratory, Benha Faculty of Engineering, Benha University, Egypt. It basically consists of a low-speed wind tunnel equipped with a nozzle and a test section. The wind tunnel is $4.5 \mathrm{~m}$ long and has a cross-section of $0.6 \mathrm{~m} \times 0.6$. It is equipped with a centrifugal fan driven by a $10 \mathrm{HP}$ three-phase AC electric motor. Air velocity through the wind tunnel is controlled by a throttling mechanism at fan inlet. A contraction nozzle was used to reduce the cross-section to fit the test section dimensions and to provide uniform flow at inlet to test section.

The test section was made of plexiglas with inlet dimension of $0.6 \mathrm{~m} \times 0.173 \mathrm{~m}$ and outlet dimension of $0.331 \mathrm{~m} \times$ $0.173 \mathrm{~m}$ as shown in Figure 2. The blade profile is similar to that used by Langston et al. [12] with blade chord length of $0.168 \mathrm{~m}$. The blade nomenclature and coordinate system is shown in Figure 3(a), and the cascade geometry data are given in Table 1. To obtain periodic flow which is essentially in linear cascade measurements, the linear cascade used in the present study contains six blades to create five flow passages as shown in Figure 2. This is similar to the linear cascade of Arts et al. [1] where periodic flow was obtained using five blades. The blades were fabricated from beech wood by using CNC machine. The blade coordinates were supplied to the machine, and the blade profile was obtained with accuracy of $1 \mu \mathrm{m}$. Flow and heat transfer measurements were obtained for the middle blade channel to avoid end effects. The two center blades were instrumented for measurements and can be replaced. Two sets of instrumented blades were prepared for individual surface static pressure and heat transfer measurements. The first set allowed surface static pressure measurements, while the second set allowed heat transfer measurements.

\subsection{Measurement Technique}

2.2.1. Flow Field Measurement. The flow field inside the cascade was measured in this study using a calibrated five-hole probe at two planes as shown in Figure 3(b). The measurement planes were located within the blade channel at $S / C=$ 0.63 and $S / C=0.89$. These planes were normal to blade suction side in the $J$-direction as denoted from suction side to next blade pressure side. The measurement grid consisted of
TABLE 1: Cascade parameters.

\begin{tabular}{lc}
\hline Number of blades & 6 \\
Blade chord length, $C[\mathrm{~mm}]$ & 168 \\
Blade axial chord, $C_{x}[\mathrm{~mm}]$ & 144 \\
Blade pitch, $P[\mathrm{~mm}]$ & 156 \\
Blade height, $H[\mathrm{~mm}]$ & 173 \\
Blade inlet angle, $\beta_{1}\left[^{\circ}\right]$ & 40 \\
Blade exit angle, $\beta_{2}\left[^{\circ}\right]$ & 65 \\
Incidence angle, $i\left[^{\circ}\right]$ & 0 \\
Stagger angle, $\gamma\left[{ }^{\circ}\right]$ & 35 \\
\hline
\end{tabular}

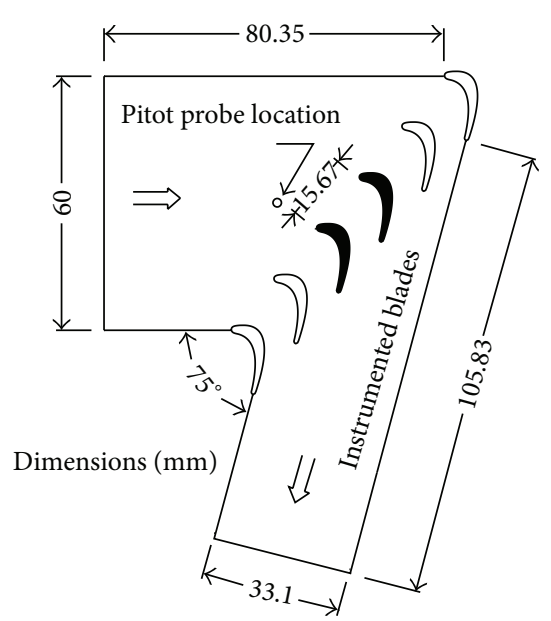

FIGURE 2: Schematic diagram of test section.

17 equal-spaced points in the $J$-direction and 12 points in the spanwise direction with refining near the end-walls. The measurements were performed for the blade half-span since the flow is symmetry along midspan plane.

2.2.2. Blade Static Pressure Measurements. The two blades forming the central flow channel were instrumented with static pressure tapping for surface pressure measurements. Pressure taps were made of stainless steel needles with inner diameter of $1.3 \mathrm{~mm}$ and outer diameter of $1.6 \mathrm{~mm}$ connected to a digital micromanometer via plastic tubes of $1.3 \mathrm{~mm}$ inside diameter, $2 \mathrm{~mm}$ outside diameter, and $1.5 \mathrm{~m}$ long. The pressure taps were placed at levels of $0.5,0.25$, and 0.875 blade span as shown in Figure 4(a). There were 19 pressure taps located at each level through blade height, 9 taps on the blade pressure surface, and 10 pressure taps on the blade suction surface. The taps were connected to the digital micromanometer with full scale of $3700 \mathrm{~Pa}$ and accuracy of $0.3 \%$ of the full scale.

2.2.3. Heat Transfer Instrumented Blade. Heat transfer measurements were conducted under uniform heat flux that was supplied to the blades using 29 nickel chrome boundary conditions on the blade surface. Electric heating resistance strips were cemented vertically on the outer surface of the blades with $2 \mathrm{~mm}$ spacing between adjacent strips. The strips were connected together in series using copper bus bars. The strips 


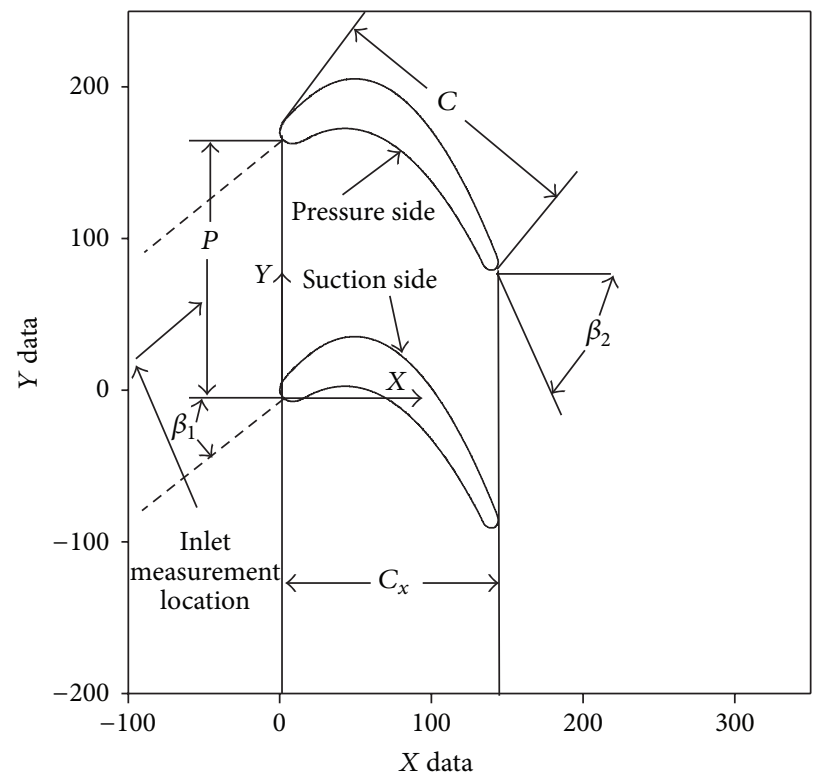

(a)

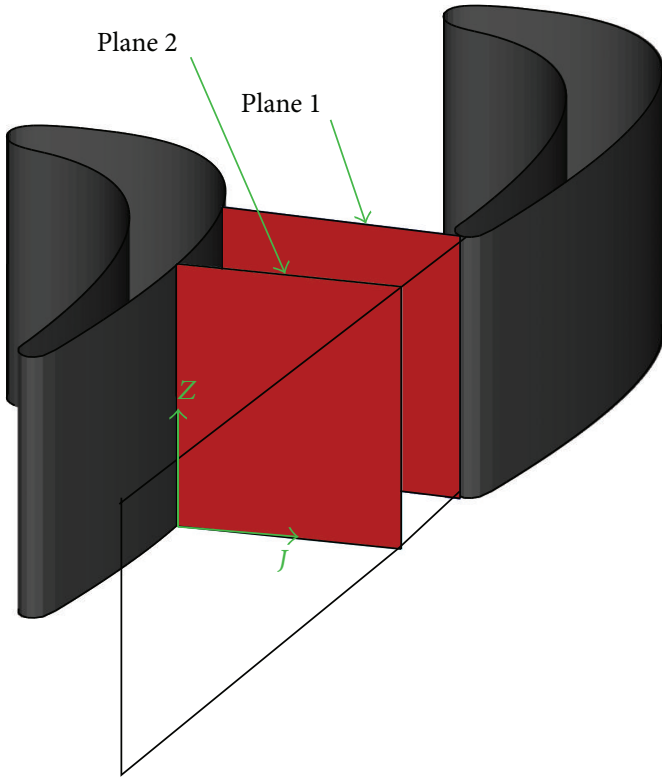

(b)

FIGURE 3: (a) Cascade parameter, coordinate system, and (b) locations of measuring planes.

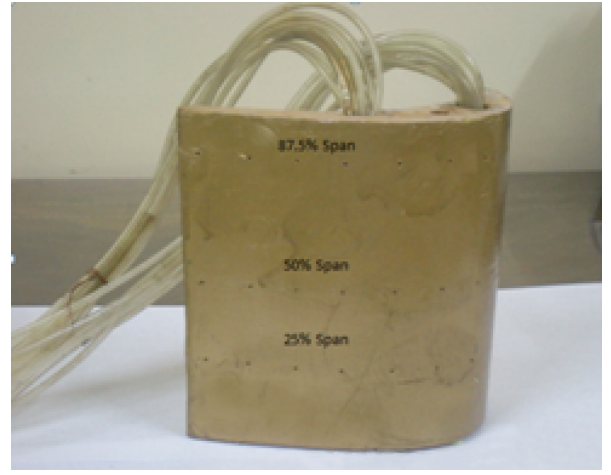

(a) Static pressure tapping

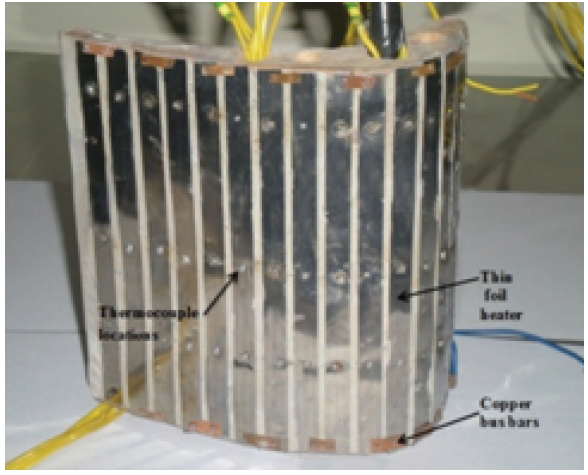

(b) Heat transfer blade

FIGURE 4: Instrumented blades.

dimensions were $173 \mathrm{~mm}$ long, $10 \mathrm{~mm}$ wide, and $0.15 \mathrm{~mm}$ thick. The suction side of the heat transfer instrumented blade is shown in Figure 4(b). The electric power was supplied to the resistance strips through a DC power supply. The required heat flux was maintained by controlling the current and voltage supplied to the strips. Sixty calibrated thermocouples of chromel-alumel were soldered on the foil strips at three different levels along blade height $(0.5,0.25$, and $0.875 \mathrm{H})$. The thermocouples were connected to a digital temperature recorder with $0.1^{\circ} \mathrm{C}$ resolution through a set of selector switches.

2.3. Measurement Procedure. A calibrated five-hole pressure probe with a tip diameter of $3 \mathrm{~mm}$ was used to measure the flow field at the inlet to the cascade at distance of $0.7 C_{x}$ upstream of the cascade. The pressures at the five holes were measured in order to determine flow conditions at the probe tip using indirect method. The relationship between the measured pressures and stagnation pressure, velocity, and flow angles was obtained from the calibration charts. Complete information on the measurements using five-hole probe and calibration procedure of the used probe can be found in ElBatsh [24]. The experiments were conducted at inlet velocities of 10,15 , and $20 \mathrm{~m} / \mathrm{s}$ corresponding to blade inlet Reynolds numbers (Re) of 106000, 159000, and 212000, respectively. The blade inlet Reynolds number is given by

$$
\operatorname{Re}=\frac{\rho U_{1} C}{\mu}
$$

where $U_{1}$ is the inlet flow velocity, $C$ is the blade chord length, $\rho$ is the air density, and $\mu$ is the fluid viscosity.

The inlet turbulence intensity was calculated using 2000 instantaneous velocity measurements. 
2.4. Data Analysis. Surface static pressure measurements were expressed as static pressure coefficient defined based on the inlet velocity as

$$
C_{P}=\frac{P_{s}-P_{1}}{0.5 \rho U_{1}^{2}},
$$

where $P_{s}$ is local static pressure distribution on the blade surface, $P_{1}$ is the inlet static pressure, and $U_{1}$ is the inlet velocity.

The local heat transfer coefficient was calculated as

$$
h=\frac{q^{\prime \prime}}{T_{w}-T_{\infty}}=\frac{q_{\text {gen }}^{\prime \prime}-q_{\text {loss }}^{\prime \prime}}{T_{w}-T_{\infty}},
$$

where $q^{\prime \prime}$ is the net local convective heat flux from the foil strips, $q_{\text {gen }}^{\prime \prime}$ is the generated heat flux from voltage-current measurements, $q_{\text {loss }}^{\prime \prime}$ is heat flux loss by radiation and by conduction, $T_{w}$ is the local steady state strip surface temperature, and $T_{\infty}$ is the uniform temperature at inlet of the cascade. The local Nusselt number $\mathrm{Nu}$ was calculated from

$$
\mathrm{Nu}=\frac{h C}{K},
$$

where $h$ is the local heat transfer coefficient, $C$ the blade chord length, and $K$ is air thermal conductivity.

The loss heat flux by conduction was obtained by measuring heat loss from the test blade at the condition without air flow through blade channel. This was done by supplying several different input powers and getting a correlation between conduction heat loss and individual foil temperature $\left(T_{w}\right)$ at steady state. The local radiation loss was estimated using a foil emissivity of 0.95 .

Consider the following:

$$
q_{\text {loss }}^{\prime \prime}=\epsilon \sigma\left(T_{w}^{4}-T_{\infty}^{4}\right)+q_{c}^{\prime \prime} .
$$

The total heat loss was about 15 percent of the heat generated in the foil. The conduction and radiation heat loss were $6 \%$ and $9 \%$, respectively.

2.5. Measurements Uncertainty. The calculation of the Nusselt number can be represented by the following form

$$
\mathrm{Nu}=f\left(x_{1}, x_{2}, \ldots, x_{n}\right),
$$

where $x_{1}$ to $x_{n}$ are all the variables that affect the experimental determination of $\mathrm{Nu}$. The uncertainty $\Delta \mathrm{Nu}$ in the value of $\mathrm{Nu}$ was estimated based on the procedure of Holman and Gajda [25] and is expressed as follows:

$$
\Delta \mathrm{Nu}=\sqrt{\sum_{i=1}^{n}\left(\frac{\partial \mathrm{Nu}}{\partial x_{i}} \Delta x_{i}\right)^{2}},
$$

where $\Delta x_{i}$ is the uncertainty in the variable $x_{i}$. The uncertainty in the various variables used in the determination of the Nusselt number were $0.25 \%$ for the electric current, $0.25 \%$ for the electric volt, $0.2^{\circ} \mathrm{C}$ for temperature measurements, $0.0001 \mathrm{~m}$ for the distance, $0.5 \%$ for the air thermal conductivity, and $5 \%$ for the emittance of the heater strips. It was found that the uncertainty of $\mathrm{Nu}$ ranges from $4.8 \%$ to $8.6 \%$. The maximum uncertainty in $C P_{s}$, was estimated to be $7.24 \%$ for suction side and $9.54 \%$ for pressure side.

\section{Numerical Procedure}

Numerical studies have been carried out using a commercial CFD code to understand different flow features and to obtain complete information on heat transfer coefficients on the blade surface. Heat transfer and fluid flow characteristics were obtained by solving the flow governing equations, namely, continuity, momentum, energy, and turbulence. The flow is considered steady and incompressible since the flow Mach number is rather small. The computational domain is defined by the inlet plane which was placed at a distance of 0.7 axial chord upstream of the blade leading edge. The outlet plane was selected at a distance of one axial chord downstream of the blade trailing edge Figure 6. The calculations were performed for blade half-span considering that the midspan is a symmetry plane. Periodic boundaries were considered to account for the periodic flow through the cascade.

3.1. Governing Equations. The governing equations for incompressible flow are given by

$$
\begin{gathered}
\frac{\partial \bar{u}_{i}}{\partial x_{i}}=0, \\
\rho \frac{\partial \bar{u}_{i} \bar{u}_{j}}{\partial x_{i}}=-\frac{\partial \bar{p}}{\partial x_{j}}+\frac{\partial}{\partial x_{i}}\left[\mu\left(\frac{\partial \bar{u}_{i}}{\partial x_{j}}+\frac{\partial \bar{u}_{j}}{\partial x_{i}}\right)-\overline{\rho u_{i}^{\prime} u_{j}^{\prime}}\right], \\
\frac{\partial\left(\rho u_{j} E\right)}{\partial x_{j}}=\frac{\partial}{\partial x_{j}}\left(\frac{\mu}{\operatorname{Pr}} \frac{\partial E}{\partial x_{j}}\right)+\frac{\partial}{\partial x_{j}}\left(u_{j} \tau_{i j}\right),
\end{gathered}
$$

where the velocities $\bar{u}_{i}$ are mean values, $u_{i}^{\prime}$ are the fluctuating one, and $-\rho \overline{u_{i}^{\prime} u_{j}^{\prime}}$ are the Reynolds stress which are calculated using eddy viscosity turbulence models as

$$
-\rho \overline{u_{i}^{\prime} u_{j}^{\prime}}=\mu_{t}\left(\frac{\partial \bar{u}_{i}}{\partial x_{j}}+\frac{\partial \bar{u}_{j}}{\partial x_{i}}\right)-\frac{2}{3} \rho k \delta_{i j} .
$$

The eddy or turbulent viscosity $\mu_{t}$ was calculated in this study using the shear stress transport SST $k-\omega$ model; $\delta_{i j}$ is the kronecker second-order tensor given by

$$
\delta_{i j}= \begin{cases}1 & \text { if } i=j \\ 0 & \text { if } i \neq j .\end{cases}
$$

Bardina et al. [26] discussed the performance of different turbulence models. They found that the SST $k-\omega$ model can predict the flows with strong adverse pressure gradients and separation. The SST $k-\omega$ model is an empirical model based on model transport equations for the turbulence kinetic energy $k$ and the specific dissipation rate $\omega$. Eddy or turbulent viscosity is calculated as

$$
\mu_{t}=\frac{\rho k / \omega}{\max \left(1 ; \Omega F_{2} /\left(a_{1} \omega\right)\right)} .
$$

In the turbulent boundary layers, the maximum value of the eddy viscosity is limited by forcing the turbulent shear stress to be bounded by the turbulent kinetic energy time $a_{1}$. This 


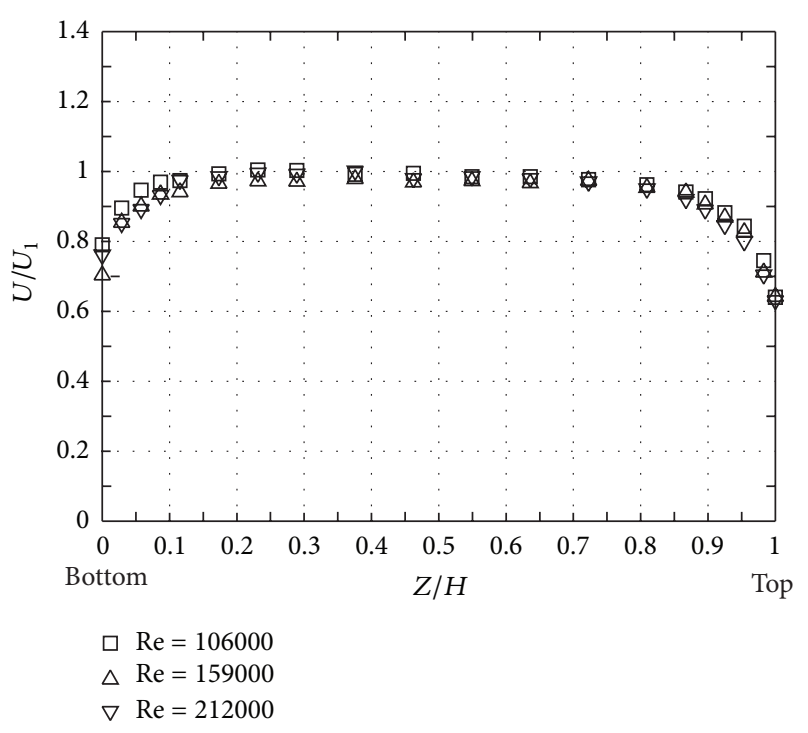

FIGURE 5: Inlet velocity profile.

effect is achieved with the auxiliary function $F_{2}$ and the absolute value of vorticity $\Omega$. The auxiliary function $F_{2}$ is defined as a function of wall distance $y$ as

$$
F_{2}=\tanh \left\{\left[\max \left(2 \frac{\sqrt{k}}{0.09 \omega y} ; \frac{500 \mu}{\rho y^{2} \omega}\right)\right]^{2}\right\}
$$

The transport equations as developed by Menter [27] and presented by Bardina et al. [26] are

$$
\begin{gathered}
\frac{\partial}{\partial x_{j}}\left[\rho k \bar{u}_{j}-\left(\mu+\sigma_{k} \mu_{t}\right) \frac{\partial k}{\partial x_{j}}\right]=\tau_{i j} S_{i j}-\beta^{*} \rho \omega k, \\
\frac{\partial}{\partial x_{j}}\left[\rho \omega \bar{u}_{j}-\left(\mu+\sigma_{\omega} \mu_{t}\right) \frac{\partial \omega}{\partial x_{j}}\right] \\
=P_{\omega}-\beta \rho \omega^{2}+2\left(1-F_{1}\right) \frac{\rho \sigma_{\omega 2}}{\omega} \frac{\partial k}{\partial x_{j}} \frac{\partial \omega}{\partial x_{j}} .
\end{gathered}
$$

$P_{\omega}$ is the production term of $\omega$, and the function $F_{1}$ is designed to blend the model coefficient in the boundary layer zones. The constants of the model are $a_{1}$ and $\beta^{*}$. Model coefficients are $\beta, \gamma^{\prime}, \sigma_{k}$, and $\sigma_{w}$. Complete details on the model can be obtained from the original papers.

3.2. Boundary Conditions. The velocity profile of the incoming flow was obtained from the current experimental measurements and was applied at the inlet boundary for different Reynolds numbers considered in this study. Figure 5 shows the inlet velocity profiles at inlet velocities of 10,15 , and $20 \mathrm{~m} / \mathrm{s}$ corresponding to inlet Reynolds numbers of 106000, 159000, and 212000 , respectively. The figure shows that the inlet velocity profile is essentially uniform between 0.2 and 0.75 blade height. The turbulence intensity was set at inlet as $1 \%$ as measured in the present study, while the turbulence length scale was considered as $0.001 \mathrm{~mm}$ based on the general guidelines for CFD calculation [28]. The inlet temperature was

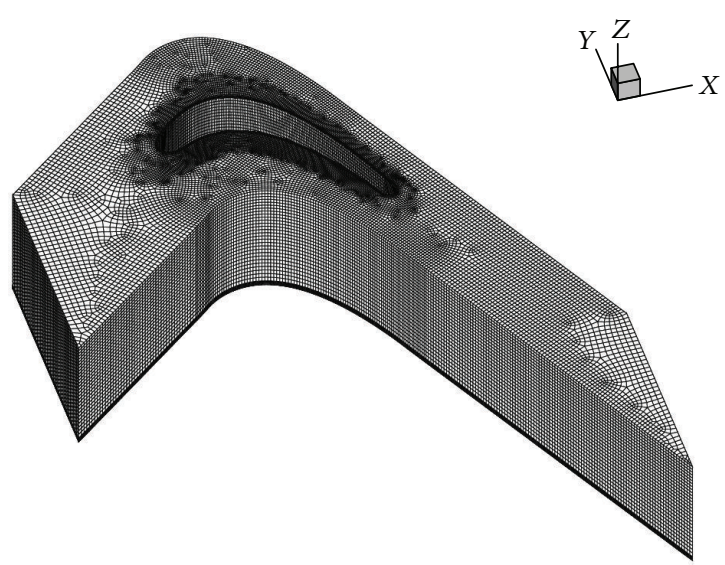

FIGURE 6: Computational grid.

considered as the measured ambient temperature at $T_{\infty}=$ $290 \mathrm{~K}$. The nonslip wall boundary condition was considered at the blade surface and at the end-wall. Constant heat flux boundary condition was considered at the blade surface obtained from the experimental procedure.

3.3. Grid Generation. The three-dimensional unstructured grid was generated using the preprocessor software Gambit, release 2.3.16. A two-dimensional mesh was generated to solve the midspan flow and to obtain the appropriate near wall distance corresponding to dimensionless wall distance $y^{+}$smaller than 1 which is necessary to solve the viscous sublayer. The two-dimensional grid was created using unstructured topology with quadrilateral elements. A boundary layer region was used around the blade consisting of structured O-type mesh to allow fine grid near the solid walls. Several trials were performed until the dimensionless wall distance $y^{+}$was about 0.6 which is a prerequisite for the solution of the viscous sublayer and heat transfer near the walls. The volume mesh was created by copying the two-dimensional grid in the spanwise direction. Boundary layer zones were also specified at the end-wall to solve the flow near the wall. Figure 6 shows the computational grid.

3.4. Grid Independence Study. The solution grid dependency was examined at inlet Reynolds number of 106000 . Four grids were used to check the grid dependency with total numbers of cell of 661160, 1090914, 1652900, and 1818190 for the half-span. The effect of grid size on the local heat transfer coefficient was examined. The calculations indicated that for all grid sizes, the midspan heat transfer showed grid independent solution.

The comparison at the level corresponding to spanwise distance of $0.125 \mathrm{H}$ showed also grid independent results. However, the spanwise distance corresponding to $0.25 \mathrm{H}$ showed grid dependence on the blade suction surface. Figure 7 shows the comparison between Nusselt number obtained using different grid sizes. The figure indicates that there is no significant change in Nusselt number when the mesh size increased above 1652900. Except for the $S / C=$ 0.8638 , and 0.9538 points on suction side, increasing the 


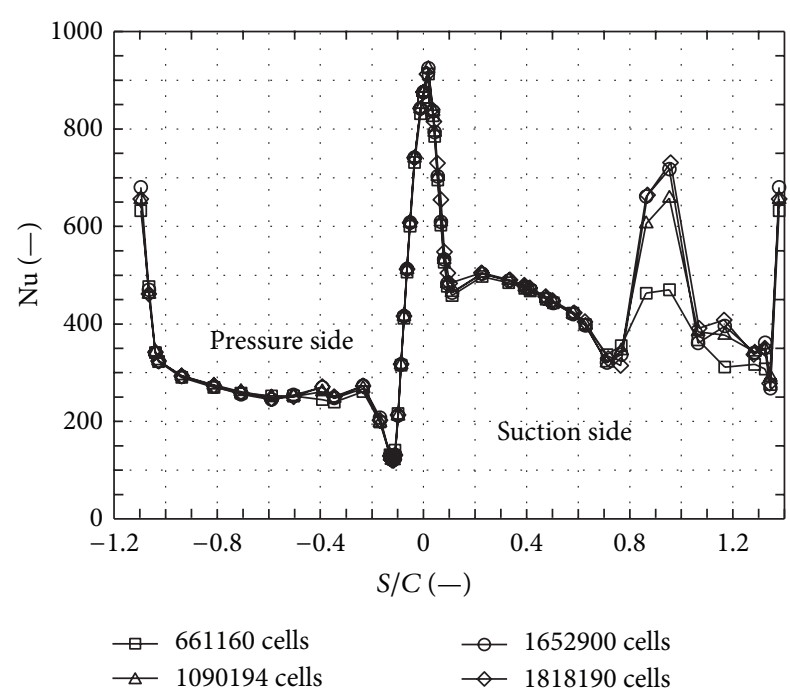

FIGURE 7: Heat transfer coefficients for different meshes.

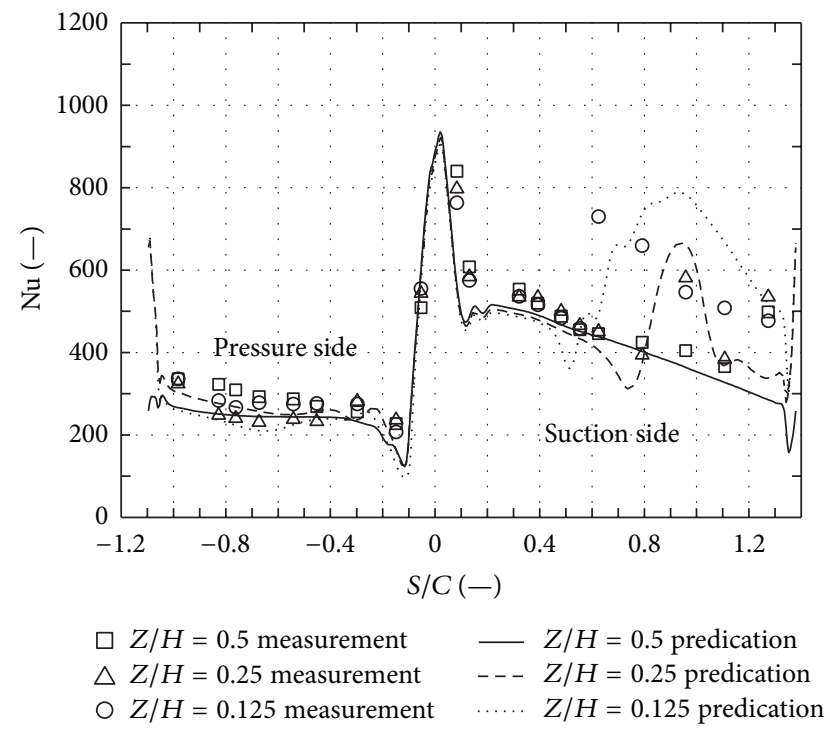

FIgURE 8: Nusselt number distribution on the blade surface at different spanwise locations, $\mathrm{Re}=106000$.

total number of cell from 1652900 to 1818190 , the Nusselt number increases by $0.48 \%$ and $1.89 \%$ for $S / C=0.8638$ and $S / C=0.9538$, respectively. Therefore, grid independent solution was obtained with almost 1652900 cells for the blade half-span.

\section{Results and Discussion}

4.1. Blade Three-Dimensional Heat Transfer. Figure 8 shows Nusselt number distribution along blade surface at different locations through blade height at inlet Reynolds number of 106000. The local Nusselt number is presented as a function of the dimensionless distance along blade surface $(S / C)$. The figure indicates that the maximum Nusselt number was predicted at the stagnation point. Then, Nusselt number

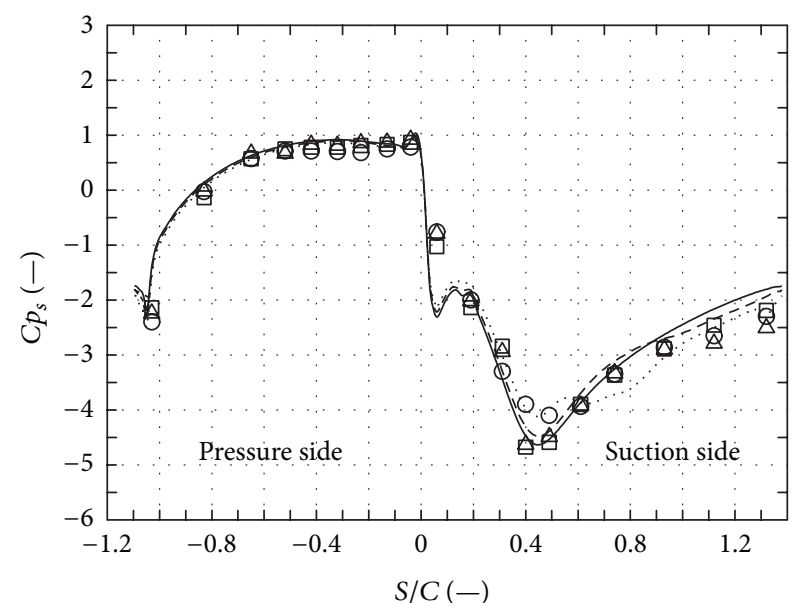

$$
\begin{aligned}
& \square Z / H=0.5 \text { measurement } \quad-Z / H=0.5 \text { predication } \\
& \triangle Z / H=0.25 \text { measurement } \quad--Z / H=0.25 \text { predication } \\
& \triangle Z / H=0.125 \text { measurement } \quad \cdots \cdot Z / H=0.125 \text { predication }
\end{aligned}
$$

Figure 9: Blade static pressure coefficient at different spanwise locations and at $\operatorname{Re}=106000$.

decreases on both blade sides. Generally, Nusselt number is higher on the blade suction surface than on the blade pressure surface. This is caused by the high velocity on the blade suction surface corresponding to the low pressure compared to the relatively low velocity and the associated Nusselt number on the blade pressure surface. On the pressure surface, Nusselt number sharply decreases near $S / C=-0.1$. The reduction in Nusselt number close to blade leading edge was extensively discussed by Choi et al. [8] which was attributed to laminar flow separation and flow reattachment on that region of pressure surface. After flow reattachment and acceleration, it gradually increases from $S / C=-0.1$ to trailing edge. On the suction surface, at midspan $Z / H=0.5$, the Nusselt number after stagnation decreased with increasing the streamwise distance from the stagnation due to boundary layer growth. Nusselt number increases sharply past $S / C=1.1$ which may be attributed to laminar to turbulent transition. In the region near the end-wall of suction side, namely, at $Z / H=0.25$ and 0.125 , the secondary flow has a dominate effect on Nusselt number. The decelerating flow region (adverse pressure gradient) evident in Figure 9, near $S / C \cong 0.4$, from this point on, the effects of secondary flow are evident. Many of the effects can be attributed to the vortex structures described by Langston et al. [12], Sieverding [13], and Wang et al. [14]. The passage vortex and the pressure side leg of the horseshoe vortex now approach the suction side surface region. Nusselt number enhanced by secondary flow impinging on the end-wall region of suction surface region as shown in Figure 10. The vortices lift off the end-wall and approach the $25 \%$ span. Previous measurements showed that the vortices exit the turbine blade at 50\% midspan Giel et al. [15].

This result is obtained by experimental measurements and confirmed by the numerical calculations. Examining wall static pressure on the blade surface, Figure 9 indicates that the flow is accelerating on the blade pressure surface from 


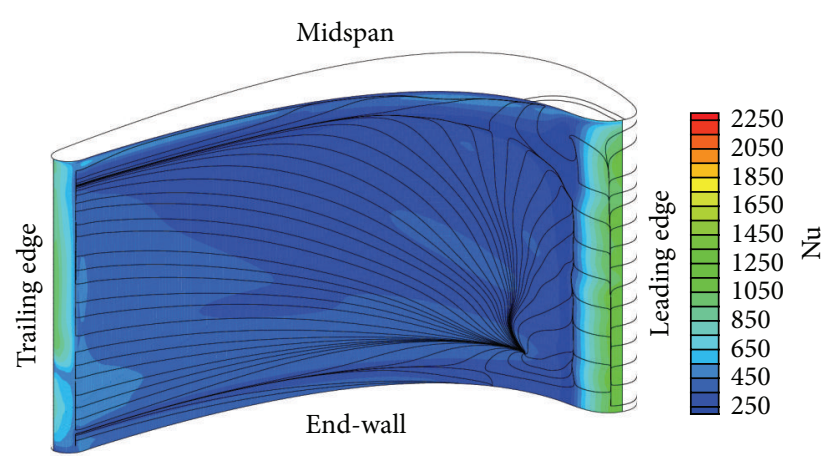

(a) Pressure side

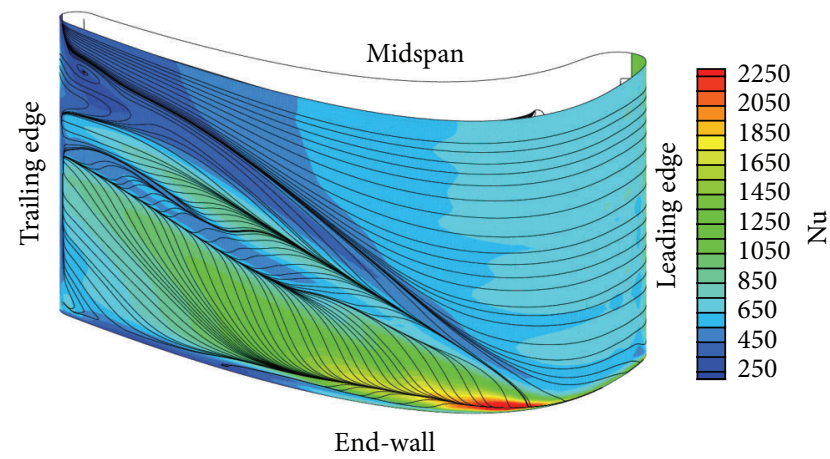

(b) Suction side

FIgURE 10: Surface Nusselt number, $\operatorname{Re}=106000$.

the $S / C=0.0$ to the trailing edge. The increase in the local velocity increases the local Nusselt number on the blade pressure surface. However, the development of the boundary layer induces thermal resistance. These two counter effects provide almost constant Nusselt number on the pressure surface. On the blade suction surface, the flow is accelerating to the location of $S / C=0.4$, and then the flow is decelerating.

Figure 10 shows wall limiting streamlines superimposed on contour plots of Nusselt number on blade pressure and suction surfaces. High Nusselt number was predicated at the blade leading edge and decreased sharply downstream on the pressure side due to boundary layer growth. Nusselt number results on the blade suction surface had the feature of a triangle region with enhanced Nusselt number located after blade midchord near the blade end-wall surface. The enhanced Nusselt number is due to the action of the passage vortex, as explained above. A close examination of the triangular region shows two separate regions of high Nusselt number, separated by a lower Nusselt number line. A large region of the enhanced heat transfer is caused by the action of passage vortex that has been drawn toward the suction surface. Above this region, a high heat transfer is caused by the action of the suction side vortex. This agrees well with the flow visualizations of Wang et al. [14].

4.2. Passage Flow Field. The detailed information on the flow field can be extracted through an analysis of the passage static pressure. The passage static pressure distribution plays a major role in driven secondary flow through blade passage. The flow field was measured for two planes with five-hole probe at a Reynolds number of 159000.

Figure 11 shows the predicated and measurements static pressure coefficient contour on plane 1 at locations $S / C=$ 0.63 . The static pressure coefficient increases on the blade pressure side and decreases on the blade suction side. The predicated minimum static pressure coefficient is showed near the end-wall suction side, with the center around $Z / H=$ 0.05 , and $J / C=0.05$, while the measurements show that the minimum static pressure coefficient near $Z / H=0.035$, and $J / C=0.025$. This indicated the presence of passage vortex at that region. This illustrate the increases of the Nusselt number at $S / C=0.63$, for $Z / H=0.125$, where $\mathrm{Nu}=700,760$ for predicated and measurements, respectively, compared to $\mathrm{Nu}=380,420$ at $Z / H=0.25$, at same point.
Moving further downstream position and at plane 2 at $S / C=0.89$, Figure 12 , the passage vortex gradually grows large in size and lifts above the end-wall as it travels along the suction side toward the passage exit. The center of the minimum static pressure coefficient is located at spanwise distance at $Z / H=0.15$, and $J / C=0.05$ for both predicated and measurements. Now, the effect of the passage vortex approach the $Z / H=0.25$ and increases the Nusselt number, as shown in Figure 8 at $S / C=0.89$. For $\operatorname{Re}_{i}=106000$, Nusselt number at $Z / H=0.25$ equal to $818.3,625$ for predicated and measurements, respectively, compared to 521, 596.32 at $S / C=0.63$.

4.3. Effect of Reynolds Number. Figure 13 shows the predicted Nusselt number from the numerical calculations and the experimentally measured local Nusselt number on blade midspan at different inlet Reynolds number, namely, 106000, 159000, and 212000. The figure shows that good agreement was obtained between numerical predictions and experimental measurements. Generally, increasing Reynolds number increases Nusselt number distribution at different locations from the blade leading edge to trailing edge. The experimental measurements show that Nusselt number increased sharply at about $S / C=1.1$ which could not be predicted by the numerical calculations. The possible reason for this discrepancy is the absence of the transition modeling in the numerical calculation. The increase in heat transfer at this location at high Reynolds number could also be attributed to flow separation.

Figures 14 to 15 show the measurement and predicated Nusselt number distribution at different levels through blade height and at Reynolds numbers of 159000 and 212000, respectively. The figures show good agreement between numerical model predictions and the experimental measurements. The same trend of Nusselt number is obtained at different Reynolds numbers. However, increasing Reynolds number increases blade heat transfer. The increase in the local Nusselt number on the blade suction near the trailing edge at $Z / H=0.25$ and 0.125 is also obtained from the measurements and confirmed by the numerical calculations. These figures indicate also that Reynolds number affects the magnitude of heat transfer on the blade pressure and suction surfaces, but the distribution trend of heat transfer coefficient does not depended on Reynolds number. 


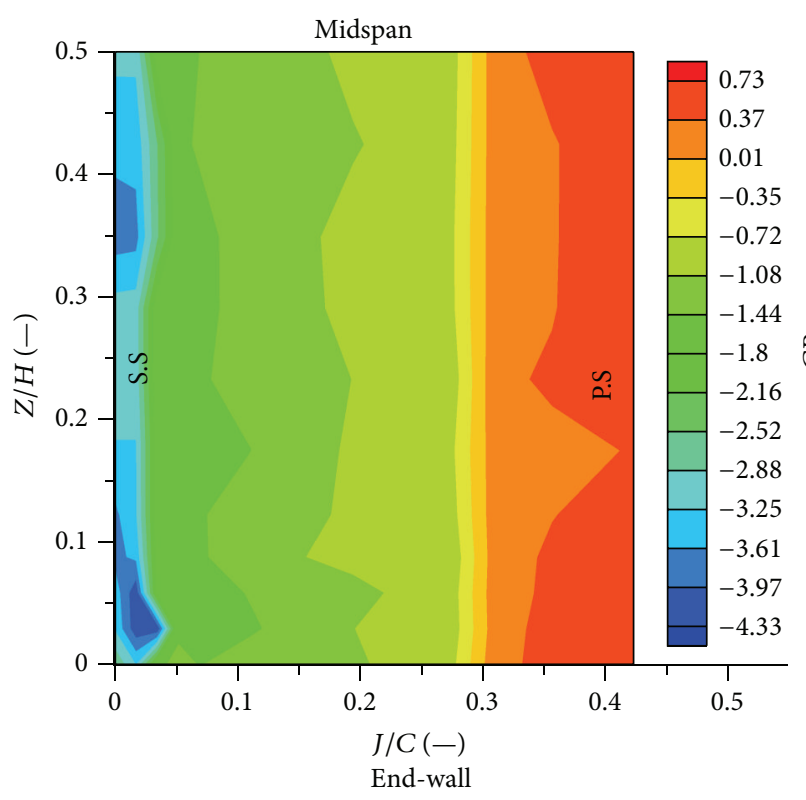

(a) Experimental

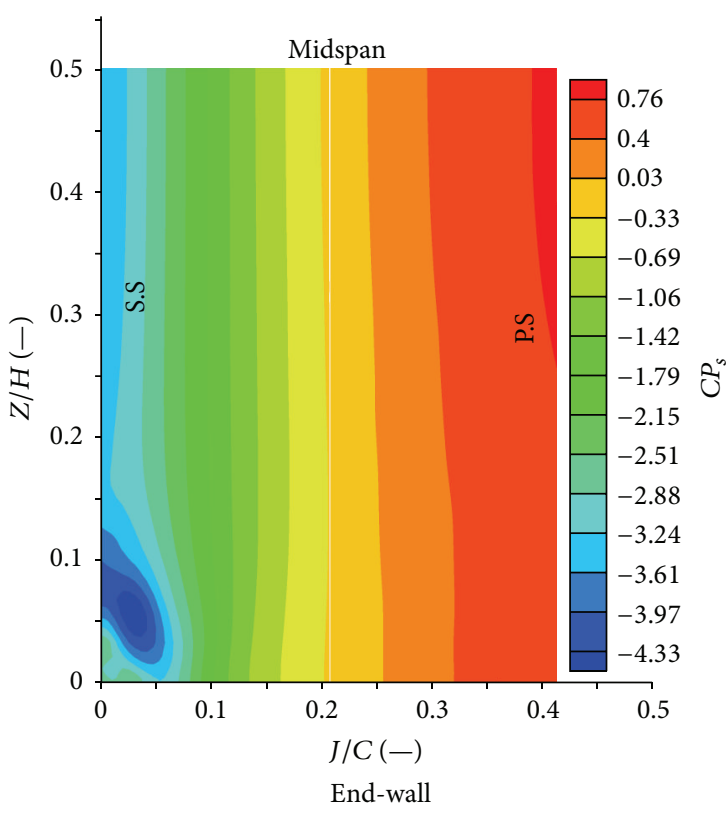

(b) Predicated

FIGURE 11: Static pressure coefficient on plane 1 at $S / C=0.63$.

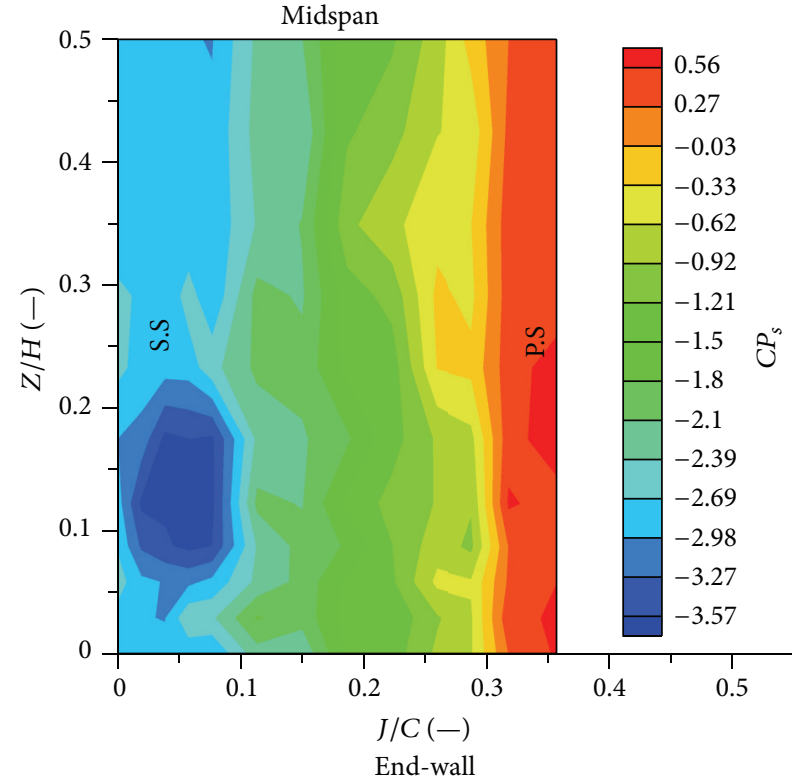

(a) Experimental

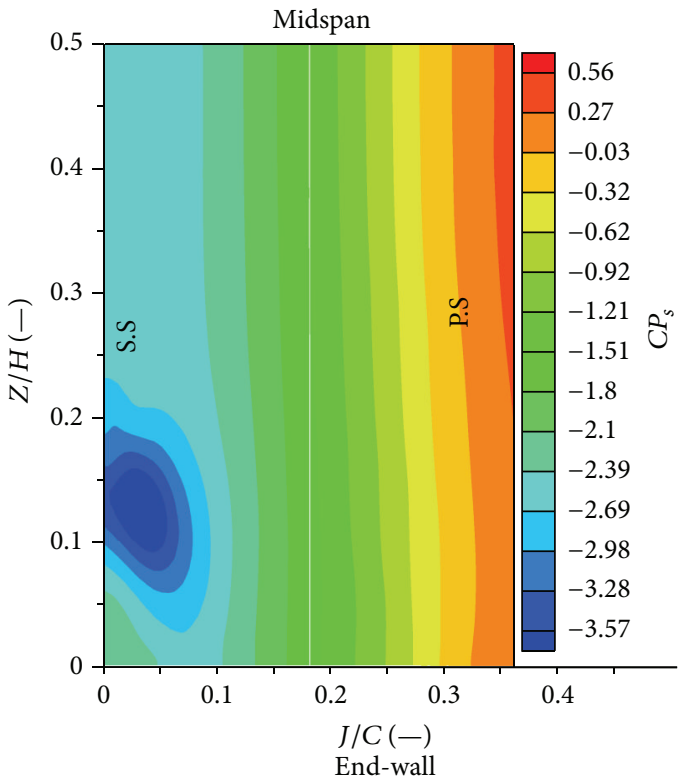

(b) Predicated

FIGURE 12: Static pressure coefficient on plane 2 at $S / C=0.89$.

Figure 16 shows the comparison of the Nusselt number at midspan region in the present study and in other researcher's experiments. For the exact comparison, the data for relatively low Reynolds numbers (the order of $10^{5}$ ) are taken for all cases. For the comparison with the present results, the levels and the Nusselt number are fairly similar, although some discrepancies are observed in certain regions because of the different blade profile and flow conditions.

\section{Conclusions}

Three-dimensional heat transfer measurements and numerical calculations were performed in this study to investigate the effect of the secondary flow on the heat transfer through turbine blades. The numerical calculations showed reasonable agreements with the experimental measurements. It was found through the study that the secondary flow increases 


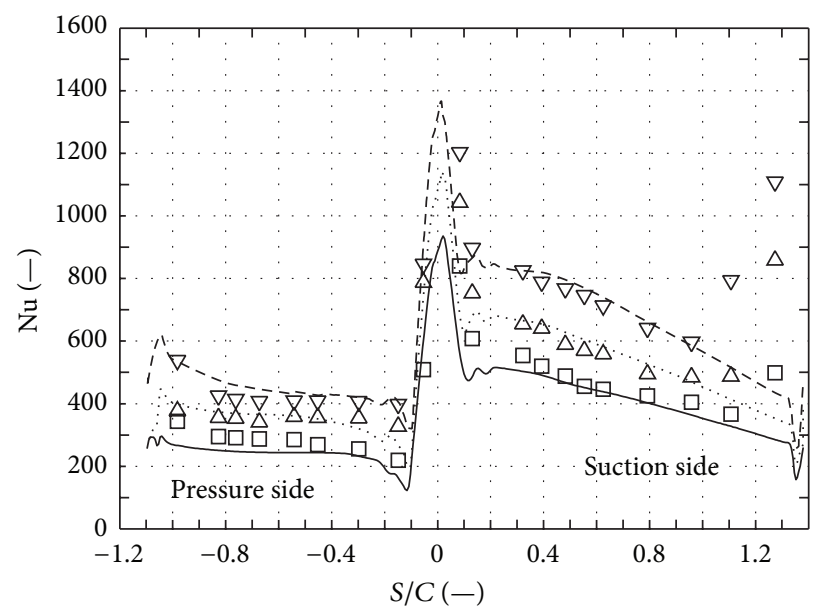

$\square \mathrm{Re}=106000$ measurement

$\triangle \operatorname{Re}=159000$ measurement

○ $R e=212000$ measurement

FIGURE 13: Effect of Reynolds number on midspan heat transfer.

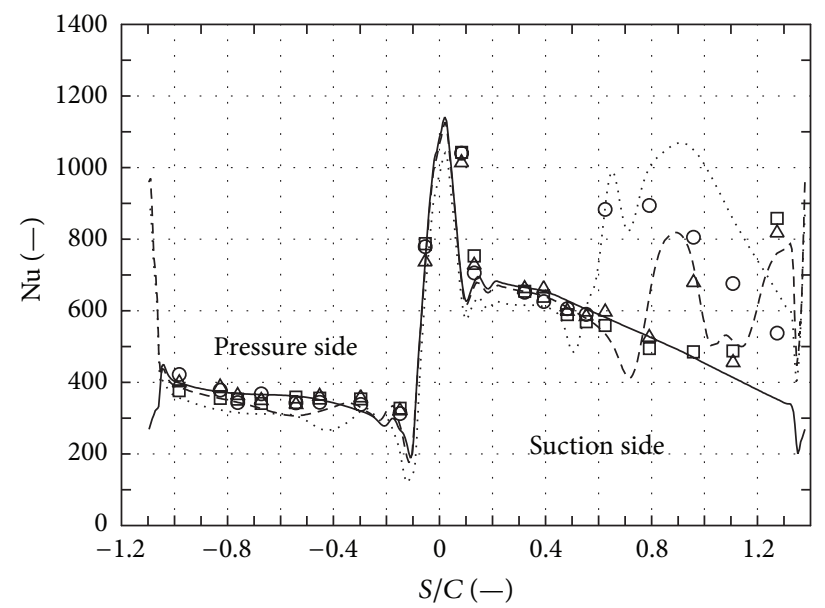
$\square Z / H=0.5$ measurement
$Z / H=0.5$ predication
$\triangle Z / H=0.25$ measurement
- - $Z / H=0.25$ predication
○ $Z / H=0.125$ measurement
… $Z / H=0.125$ predication

FIgURE 14: Nusselt number distribution at different locations through blade height, $\operatorname{Re}=159000$.

heat transfer on the blade suction surface near the blade trailing edge. Separation line was predicted by the numerical technique on the blade suction surface corresponding to the passage vortex. The separation line is characterized by high heat transfer rates. Increasing Reynolds number changes the magnitude of heat transfer coefficients keeping the same heat transfer pattern unchanged.

\section{Nomenclature}

\author{
$a_{1}[-]$ : Constant \\ $C[\mathrm{~m}]: \quad$ Chord length \\ $C_{x}[\mathrm{~m}]:$ Axial chord \\ $C P_{s}[-]$ : Static pressure coefficient
}

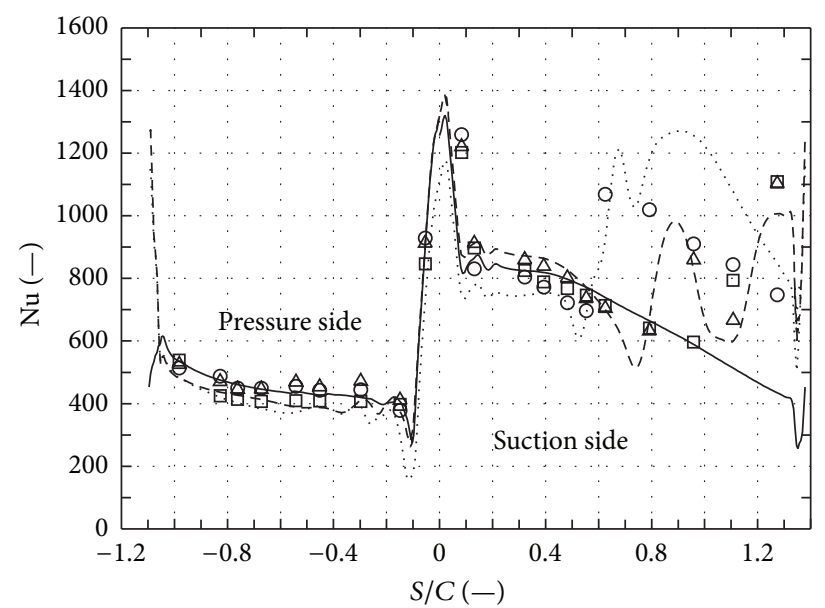
$\square Z / H=0.5$ measurement
$Z / H=0.5$ predication
$\triangle Z / H=0.25$ measurement
$Z / H=0.25$ predication
○ $Z / H=0.125$ measurement
$Z / H=0.125$ predication

FIGURE 15: Nusselt number distribution at different locations through blade height, $\mathrm{Re}=212000$.

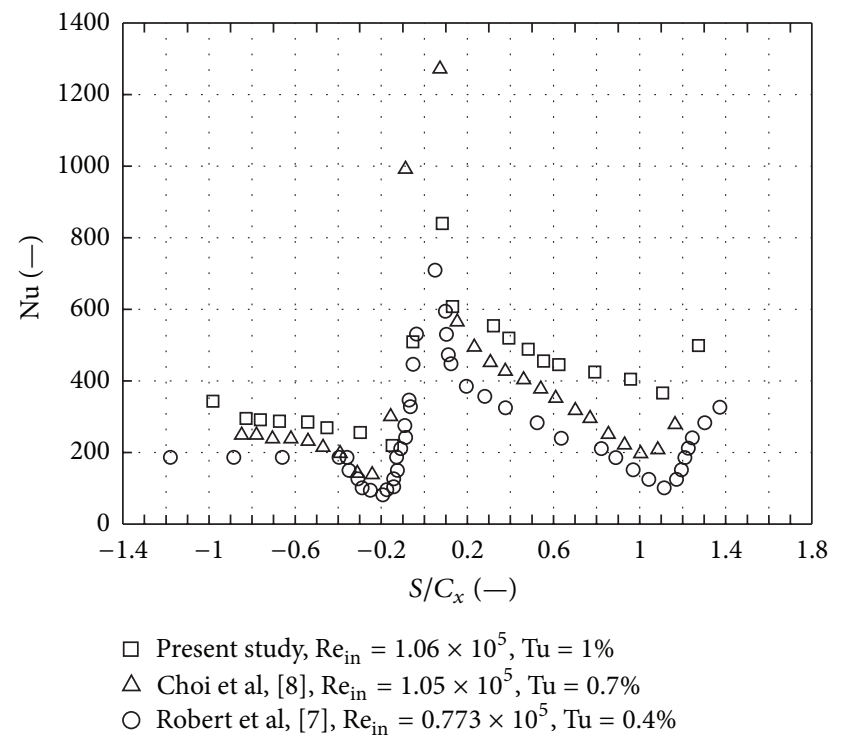

FIGURE 16: Comparison of local $\mathrm{Nu}$ distributions at midspan region.

$F_{1}, F_{2}[-]: \quad$ Functions

$h\left[\mathrm{~W} / \mathrm{m}^{2} \mathrm{~K}\right]$ : Local heat transfer coefficient

$H[\mathrm{~m}]: \quad$ Blade height

$k\left[\mathrm{~m}^{2} / \mathrm{s}^{2}\right]: \quad$ Turbulent kinetic energy

$K[\mathrm{~W} / \mathrm{mK}]:$ Air thermal conductivity

$\mathrm{Nu}[-]$ : $\quad$ Nusselt number

$P_{s}[\mathrm{~Pa}]: \quad \quad$ Static pressure

$P_{\omega}\left[\mathrm{kg} / \mathrm{m}^{3} \mathrm{~s}^{2}\right]$ : Production of $\omega$

$P[\mathrm{~m}]: \quad \quad$ Blade pitch

$q^{\prime \prime}\left[\mathrm{W} / \mathrm{m}^{2}\right]:$ Local convective heat flux

$q_{\text {gen }}^{\prime \prime}\left[\mathrm{W} / \mathrm{m}^{2}\right]:$ Generated heat flux

$q_{\text {loss }}^{\prime \prime}\left[\mathrm{W} / \mathrm{m}^{2}\right]$ : Loss heat flux

$q_{c}^{\prime \prime}\left[\mathrm{W} / \mathrm{m}^{2}\right]$ : Loss heat flux by conduction

Re [-]: Reynolds number 
$S[\mathrm{~m}]: \quad$ Distance along blade surface

$S_{i j}[1 / \mathrm{s}]:$ Mean strain rate tensor

$T_{w}[\mathrm{~K}]:$ Steady state strip temperature

$T_{\infty}[\mathrm{K}]:$ Temperature at cascade inlet

$u^{\prime}[\mathrm{m} / \mathrm{s}]$ : Fluctuating velocity

$\bar{u}[\mathrm{~m} / \mathrm{s}]:$ Mean velocity

$U[\mathrm{~m} / \mathrm{s}]:$ Mass-averaged velocity

$x_{j}[\mathrm{~m}]: \quad$ Coordinate in $j$-direction

$x[\mathrm{~m}]: \quad$ Distance through axial chord

$y[\mathrm{~m}]: \quad$ Distance along blade spacing

$y^{+}[-]$: Dimensionless wall distance

$Z$ [m]: Distance along blade height.

\section{Greek Symbols}

$\beta_{1}\left[^{\circ}\right]$ :

$\beta_{2}\left[{ }^{\circ}\right]$ :

Inlet blade angle

$\beta, \gamma^{\prime}[-]$ :

Exit blade angle

$\beta^{*}[-]:$

Model coefficients

$\epsilon[-]:$

Model constant

$\mu[\mathrm{Pa} \mathrm{s}]:$

Emissivity

$\mu_{t}[\mathrm{Pas}]:$

Molecular viscosity

$\omega[1 / \mathrm{s}]:$

Turbulent eddy viscosity

$\Omega[1 / \mathrm{s}]:$

Specific dissipation rate

$\rho\left[\mathrm{kg} / \mathrm{m}^{3}\right]: \quad$ Fluid density

$\sigma\left[\mathrm{W} / \mathrm{m}^{2} \mathrm{~K}^{4}\right]$ : Stefan-Boltzmann constant

$\sigma_{k}, \sigma_{\omega}[-]: \quad$ Model coefficients

$\tau_{i j}[-]: \quad$ Turbulent Reynolds stresses.

\section{Subscripts}

1: Inlet

2: $\quad$ Exit

$i \cdot j$ : Tensor indices.

\section{References}

[1] T. Arts, M. L. DeRouvroit, and A. W. Rutherford, "Aero-thermal investigation of a highly loaded transonic linear turbine guide vane cascade: a test case for inviscid and viscous flow computations," Tech. Rep. VKI-174, 1990.

[2] S. P. Harasgama, F. H. Tarada, R. Baumann, M. E. Crawford, and S. Neelakantan, "Calculation of heat transfer to turbine blading using two-dimensional boundary layer methods," in Proceedings of the International Gas Turbine and Aeroengine Congress and Exposition, ASME, May 1993.

[3] H. U. Jiasen and T. H. Fransson, "On the application of transition correlations in turbomachinery flow calculation," Tech. Rep. GT1998- 460, ASME, 1998.

[4] R. Pecnik and W. Sanz, "Application of the turbulent potential model to heat transfer predictions on a turbine guide vane," Journal of Turbomachinery, vol. 129, no. 3, pp. 628-635, 2007.

[5] Y. Liu, "Aerodynamics and heat transfer predictions in a highly loaded turbine blade," International Journal of Heat and Fluid Flow, vol. 28, no. 5, pp. 932-937, 2007.

[6] L. Zhang and J.-C. Han, "Influence of mainstream turbulence on heat transfer coefficients from a gas turbine blade," Journal of Heat Transfer, vol. 116, no. 4, pp. 896-903, 1994.

[7] R. J. Butler, A. R. Byerley, K. VanTreuren, and J. W. Baughn, “The effect of turbulence intensity and length scale on low-pressure turbine blade aerodynamics," International Journal of Heat and Fluid Flow, vol. 22, no. 2, pp. 123-133, 2001.

[8] J. Choi, S. Teng, J.-C. Han, and F. Ladeinde, "Effect of freestream turbulence on turbine blade heat transfer and pressure coefficients in low Reynolds number flows," International Journal of Heat and Mass Transfer, vol. 47, no. 14-16, pp. 3441-3452, 2004.

[9] A. C. Nix, T. E. Diller, and W. F. Ng, "Experimental measurements and modeling of the effects of large-scale freestream turbulence on heat transfer," Journal of Turbomachinery, vol. 129, no. 3, pp. 542-550, 2007.

[10] S. Nasir, J. S. Carullo, W.-F. Ng et al., "Effects of large scale high freestream turbulence and exit reynolds number on turbine vane heat transfer in a transonic cascade," Journal of Turbomachinery, vol. 131, no. 2, pp. 1-11, 2009.

[11] V. K. Garg and A. A. Ameri, "Two-equation turbulence models for prediction of heat transfer on a transonic turbine blade," International Journal of Heat and Fluid Flow, vol. 22, no. 6, pp. 593-602, 2001.

[12] L. S. Langston, M. L. Nice, and R. M. Hooper, "Three-dimensional flow within a turbine cascade passage," Journal of Engineering Power, vol. 99, no. 1, pp. 21-28, 1977.

[13] C. H. Sieverding, "Recent progress in the understanding of basic aspects of secondary flows in turbine blade passages," Journal of Engineering for Gas Turbines and Power, vol. 107, no. 2, pp. 248257,1985

[14] H. P. Wang, S. J. Olson, R. J. Goldstein, and E. R. G. Eckert, "Flow visualization in a linear turbine cascade of high performance turbine blades," Journal of Turbomachinery, vol. 119, no. 1, pp. $1-8,1997$.

[15] P. W. Giel, G. J. van Fossen, and R. J. Boyle, "Blade heat transfer measurements and predications in a transonic turbine cascade," Tech. Rep. 209296, NASA, 1999.

[16] R. Pecnik, P. Pieringer, and S. Sanz, "Numerical investigation of the secondary flow of a transonic turbine stage using turbulence closures," Tech. Rep. GT2005- 68754, ASME, 2005.

[17] H. Johan, C. Valery, L. Jonas, and L. Lennart, "Numerical validations of secondary flows and loss development downstream of a highly loaded low pressure turbine outlet guide vane cascade," Tech. Rep. GT2007-27712, ASME, 2007.

[18] M. Papa, Influence of blade leading edge geometry and upstream blowing on the heat/mass transfer in a turbine cascade [Ph.D. thesis], University of Minnesota, 2006.

[19] S. W. Lee and J. J. Park, "Effects of incidence angle on endwall convective transport within a high-turning turbine rotor passage," International Journal of Heat and Mass Transfer, vol. 52, no. 25-26, pp. 5922-5931, 2009.

[20] S. P. Lynch, N. Sundaram, K. A. Thole, A. Kohli, and C. Lehane, "Heat transfer for a turbine blade with nonaxisymmetric endwall contouring," Journal of Turbomachinery, vol. 133, no. 1, pp. 0110019-1-0110019-9, 2011.

[21] S. P. Lynch, K. A. Thole, A. Kohli, and C. Lehane, "Computational predictions of heat transfer and film-cooling for a turbine blade with nonaxisymmetric endwall contouring," ASME Journal of Turbomachinery, vol. 133, no. 4, pp. 041003-1-041003-10, 2011.

[22] E. C. Morata, N. Gourdain, F. Duchaine, and L. Y. M. Gicqel, "Effects of free stream turbulence on high pressure turbine blade heat transfer predicated by structured and unstructured LES," International Journal of Heat and Mass Transfer, vol. 55, no. 2122, pp. 5754-5768, 2012. 
[23] I. Qureshi, A. D. Smith, K. S. Chana, and T. Povey, "Effect of temperature nonuniformity on heat transfer in an unshrouded transonic HP turbine: an experimental and computational investigation," Journal of Turbomachinery, vol. 134, no. 1, pp. 011005-1-011005-12, 2012.

[24] H. M. El-Batsh, "Effect of the radial pressure gradient on the secondary flow generated in an annular turbine cascade," International Journal of Rotating Machinery, vol. 2012, Article ID 509209, 14 pages, 2012.

[25] J. P. Holman and W. J. Gajda, Experimental Method For Engineering, McGraw Hill, New York, NY, USA, 1989.

[26] J. E. Bardina, P. G. Huang, and T. J. Coakley, "Turbulence modeling validation, testing and development," NASA Technical Memorandum 110446, 1997.

[27] F. R. Menter, "Two-equation eddy-viscosity turbulence models for engineering applications," AIAA Journal, vol. 32, no. 8, pp. 1598-1605, 1994.

[28] M. Casey and T. Wintergerste, ERCOFTAC Special Interest Group on Quality and Trust in Industrial CFD, Best Practices Guidelines, 2000. 

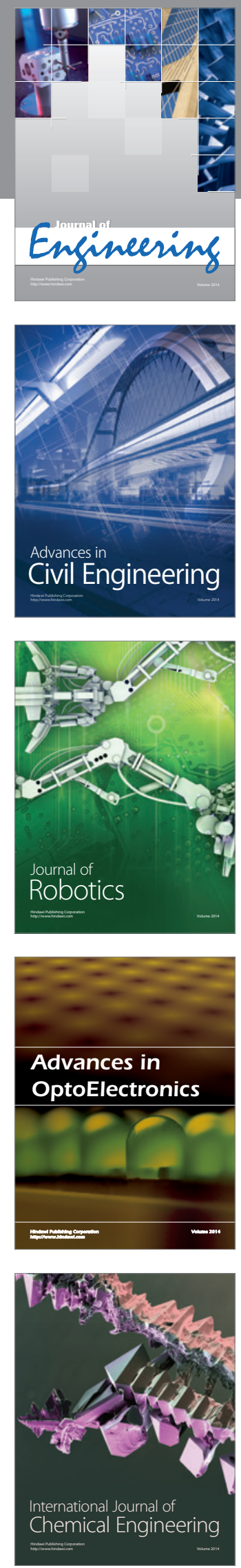

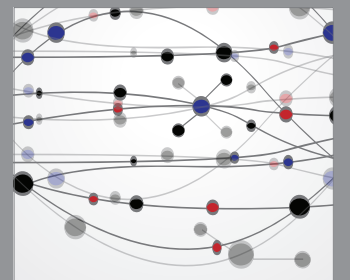

The Scientific World Journal
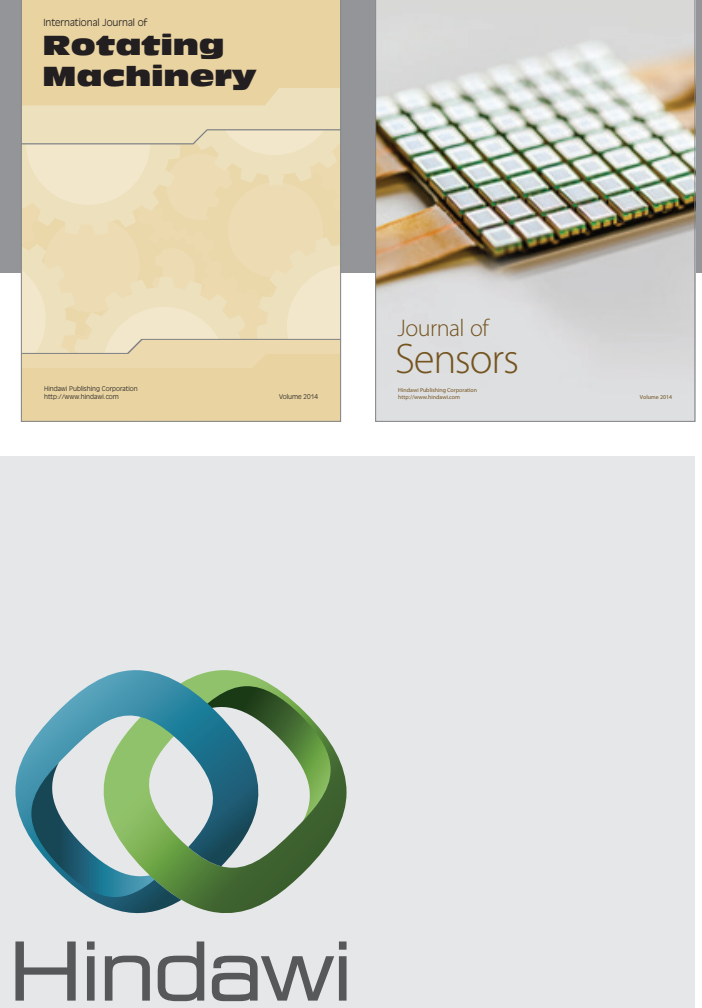

Submit your manuscripts at http://www.hindawi.com
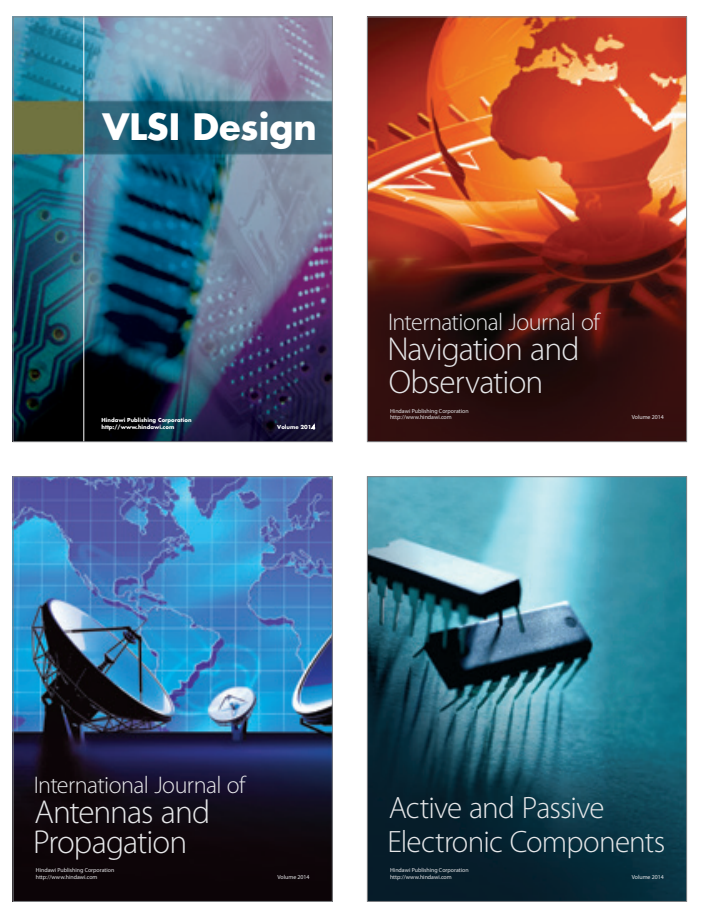
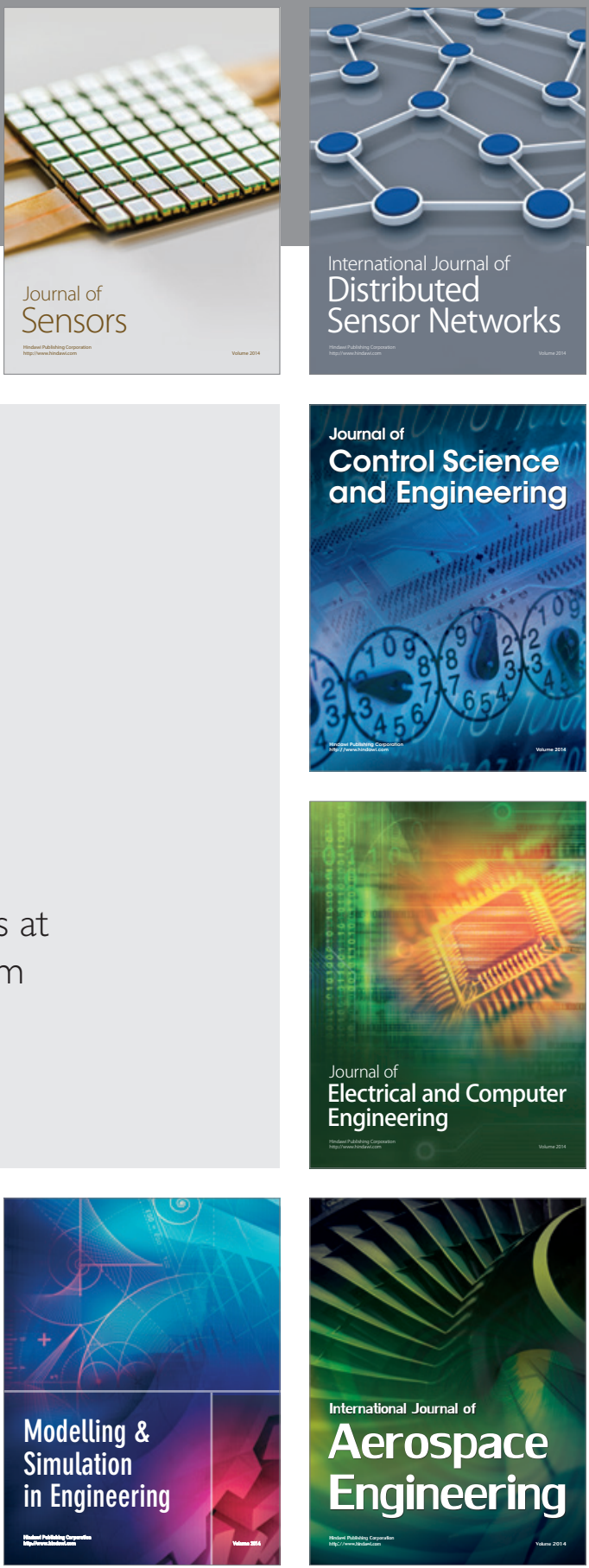

Journal of

Control Science

and Engineering
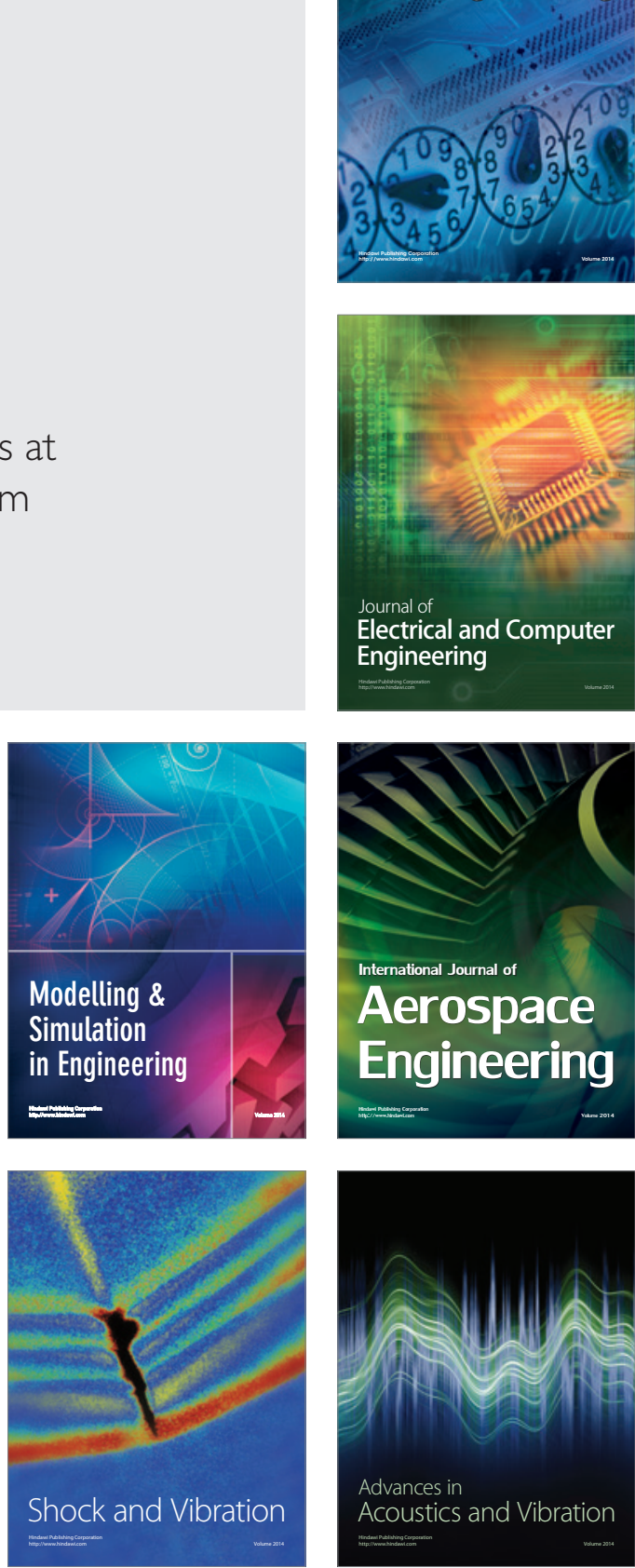